Cahiers de recherches médiévales

Odyssées maritimes et translatio vers la cité de Dieu dans le manuscrit de l'Ovide Moralisé, Rouen BM 0.4 Le message politique des livres 12 à 14

\title{
Virginie Minet-Mahy
}

\section{OpenEdition Journals}

Édition électronique

URL : https://journals.openedition.org/crm/6162

DOI : $10.4000 / \mathrm{crm} .6162$

ISSN : $1955-2424$

Éditeur

Honoré Champion

Édition imprimée

Date de publication : 20 juin 2008

Pagination : 307-332

ISSN : 1272-9752

Référence électronique

Virginie Minet-Mahy, «Odyssées maritimes et translatio vers la cité de Dieu dans le manuscrit de l'Ovide Moralisé, Rouen BM 0.4 ", Cahiers de recherches médiévales [En ligne], 15 | 2008, mis en ligne le 20 juin 2011, consulté le 15 décembre 2022. URL : http://journals.openedition.org/crm/6162 ; DOI : https://doi.org/10.4000/crm.6162 


\title{
बRM
}

\section{Odyssées maritimes et translatio vers la cité de Dieu dans le manuscrit de l'Ovide Moralisé, Rouen BM 0.4. Le message politique des livres 12 à 14}

\begin{abstract}
This article studies how the books 12 to 14 of the Ovide Moralise carry an important political message and intend to be a kind of principis regimen. Recent studies on the translation of Ovidian Metamorphosis at the beginning of the $14^{\text {th }}$ century haven't taken into account this opinion, concentrating on the predication book hypothesis. In the books 12 to 14 where the Trojan myth and the narration of the new city foundation, Rome are very important. Clergy and rhetoric competence of the characters, especially of Ulysses, prophetic voices (Sybille and Enee), apocalyptic discourses and power imaginary (Moses and mystical wedding) induce a political interpretation. In this way, the analysis of the translation, of the allegorical interpretations and the organization of the manuscript of Rouen BM 0.4 (iconography and structure of the text) enlarge the perspective suggesting a curial and ecclesiological reception
\end{abstract}

Résumé : Les livres 12 à 14 de l'Ovide Moralisé véhiculent un message politique et s'érigent en " miroir de prince ». Les études récentes sur la traduction des Métamorphoses d'Ovide au début du XIV siècle n'ont pas souligné cet aspect de l'œuvre, se limitant à l'hypothèse du livre de prédication. Du livre 12 à 14, le mythe troyen et la fondation de Rome tiennent une place importante, ainsi que l'insistance sur la clergie des personnages, Ulysse en particulier. La voix prophétique (Sybille et Enée), le discours apocalyptique et l'imaginaire du pouvoir (Moïse et le mariage mystique) orientent la lecture vers le politique. Dans cette perspective, l'analyse de la traduction, des interprétations allégoriques et de l'organisation du manuscrit de Rouen BM 0.4 (l'iconographie et la structuration du texte) ouvrent des pistes sur la réception curiale et ecclésiologique du texte.

\section{Ovide moralisé: livre de prédication, encyclopédie ou miroir de prince?}

L'Ovide moralisé1, texte anonyme, première traduction intégrale en vers des Métamorphoses d'Ovide au début du XIV ${ }^{\mathfrak{e}}$ siècle (1316-1325) accompagnée de gloses allégoriques, fait l'objet depuis une quinzaine d'années d'un regain d'intérêt ${ }^{2}$. Le texte complexe à maints égards, notamment par sa longueur et par l'obscurité relative de l'intention et de la destination du projet, donne lieu à des hypothèses

\footnotetext{
${ }^{1}$ Ovide moralisé. Poème du commencement du quatorzième siècle, éd. Cornelis De Boer, 5 t., Amsterdam, Johannes Müller, 1915-1938. Pour notre étude des livres 12 à 14, voir le t. 4 : Livres X-XIII (deel 37) et le t. 5 : Livres XIV et XV (deel 43). Pour le texte d'Ovide, nous citons d'après la traduction : Ovide, Les Métamorphoses, trad. par Joseph Chamonard, Paris, GF Flammarion, 1966.

${ }^{2}$ Je me limite à citer la thèse de M. Possamaï-Perez, L'Ovide moralisé. Essai d'interprétation, Paris, Champion, 2006
}

Cahiers de Recherches Médiévales, 15, 2008 
stimulantes et à approfondir : l'Ovide moralisé est-il un livre de prédication ou de matière pour le sermon ${ }^{3}$ ? Une somme encyclopédique ${ }^{4}$ et littéraire? Un art de mémoire $^{5}$ ? Il est un genre auquel on n'a pas encore beaucoup tenté de rattacher le texte: le miroir des princes. Pourtant, la tradition manuscrite plaide plus en faveur d'une réception curiale de l'œuvre que pour l'hypothèse restrictive d'un outil de prêche. Rappelons que selon une thèse déjà ancienne, le manuscrit de Rouen aurait été destiné à la reine Jeanne de Bourgogne, épouse du roi Philippe $\mathrm{V}^{6}$. L'Ovide moralisé étant conservé dans des livres de nobles richement enluminés ${ }^{7}$, il y a de fortes chances pour qu'il s'adresse aussi à une élite aristocratique engagée dans la vie publique et par là invitée à soigner son édification morale et spirituelle, tout en goûtant le plaisir de la fable et la profondeur de l'enseignement ${ }^{8}$. L'association incongrue entre histoires d'amour, d'inceste, de viol, de tromperie d'une part et les lectures mariales, ecclésiologiques, eucharistiques d'autre part'se trouverait dans cette perspective intégrée à un unique projet : travailler à la sagesse morale du prince par le plaisir de la lettre et la saveur de la senefiance.

\footnotetext{
${ }^{3}$ M. R. Jung, «Aspects de l'Ovide moralisé », Ovidius Redivivus. Von Ovid zu Dante, éd. par Michelangelo Picone et Bernhard Zimmerman, Stuttgart, Metzel, 1994, p. 149-172. J.-Y. Tilliette, «L'écriture et sa métaphore. Remarques sur l'Ovide moralisé», "Ensi firent li ancessor ». Mélanges de Philologie médiévale offerts à Marc-René Jung, publiés par L. Rossi avec la collaboration de C. Jacob-Hugon et U. Bähler, Alessandria, Edizioni dell'Orso, 1996, p. 543-558. M. Possamaï (op. cit) dévelope la thèse de Jung et Tilliette et tente, selon leur méthode, de ramener chaque livre à un thème et d'y déceler des mots-clés et des images stéréotypes. Elle nuance l'hypothèse du texte comme recueil de sermons, vu la longueur notamment de chaque livre et penche plutôt pour un recueil de matière utilisable dans les sermons. Le caractère mnémonique de certaines parties, notamment les ekphrasis nombreuses, aiderait la mémorisation. On reviendra sur cette lecture.

${ }^{4}$ B. Ribémont, «L'Ovide moralisé et la tradition encyclopédique. Une approche générique comparative ", Cahiers de Recherches Médiévales (XIII $-X V^{e}$ siècles). Lectures et usages d'Ovide, 9, 2002, p. 13-25.

${ }^{5}$ Pour une synthèse des diverses opinions énumérées, je renvoie à l'étude de M. Possamaï.

${ }^{6}$ Pour une claire mise au point, voir M.-R. Jung, «Les éditions manuscrites de l'Ovide moralisé », Cahiers d'Histoire des Littératures romanes, 20, 1996, p. 251-274, p. 255 en particulier. Le texte de l'Ovide moralisé daterait d'entre 1316 et 1325 . L'hypothèse de la destination du manuscrit de Rouen à Jeanne de Bourgogne est basée sur le prologue de l'Ovidius moralizatus de Pierre Bersuire, pas sur des preuves internes au texte ou au manuscrit.

${ }^{7}$ Voir M.-R. Jung, «Les éditions manuscrites de l'Ovide moralisé », Cahiers d'Histoire des Littératures romanes, 20, 1996, p. 251-274.

${ }^{8}$ Sur la notion de recréation et la fonction morale du divertissement, voir : Joël Blanchard, «Le corps du roi : mélancolie et "recréation". Implications médicales et culturelles du loisir des princes à la fin du Moyen Âge ", Représentation, pouvoir et royauté à la fin du Moyen Âge. Actes du colloque organisé par l'Université du Maine les 25 et 26 mars 1994, éd. Joël Blanchard, Paris, Picard, 1995, p. 199-211.

${ }^{9}$ Sur ce type de problèmes, voir: V. Minet-Mahy, «Quelques traces d'une «théorie du texte » dans l'allégorèse en moyen français. La fiction, moteur de la quête du sens ? », Le Moyen Age, 110/ 3-4, 2004, p. 595-626.
} 
Dans ce vaste ensemble de 72000 vers, les livres 12-13-14 se présentent comme un lieu potentiellement propice au projet de miroir ${ }^{10}$. La matière de Troie domine. Celle-ci hante depuis longtemps l'imaginaire des origines mythiques des royautés occidentales ${ }^{11}$.

Les livres 12 à 14 de l'Ovide moralisé semblent mettre en évidence, à travers essentiellement les personnages d'Ulysse et d'Énée, des doubles engagés dans une odyssée maritime, deux modèles de prise de parole qui correspondent à l'évolution de la conscience de l'auteur engagé sur le champ public et définis par Jean-Claude Mühlethaler : le philosophe et le prophète ${ }^{12}$. Le rapport des personnages à la parole et surtout aux pouvoirs de celle-ci dans le procès de Salut de l'humanité, de la nef de l'Église (la métaphore de la navigation s'impose dans les aventures des deux personnages et dans la glose chrétienne) se manifeste clairement à la fois aux niveaux des modifications de la traduction (les interpolations de matière absente des Métamorphoses d'Ovide et les changements par rapport au texte d'Ovide), au niveau des gloses allégoriques et de l'organisation matérielle du manuscrit de Rouen BM 0.4 , dans le programme iconographique et dans le système de structuration et de repère mémoriel que constituent les lettrines ${ }^{13}$. Par le biais d'une analyse de ces trois éléments (narration antique-glose chrétienne et éléments de structuration et d'interprétation dus à l'organisation matérielle), je voudrais montrer en quoi les livres 12 à 14 de l'Ovide moralisé véhiculent un message d'ordre ecclésiologique et politique en particulier grâce aux figures de la métis et de la prophétie, à l'imaginaire apocalyptique et politique.

Dans l'Ovide moralisé, l'art de la parole rusée ou prophétique se pose comme acteur principal de la réformation du monde. Elle participe à la sagesse des héros en quête de leur royaume et pour Énée, à la construction de Rome, une cité céleste. Le traducteur glossateur tire parti des figures d'Ulysse, prince de la parole et de

\footnotetext{
${ }^{10}$ Genre assez polymorphe et qui évolue assez notablement au XIV ${ }^{\mathrm{e}}$ siècle. Pour une mise au point, voir l'ouvrage: J. Blanchard et J.-Cl. Mühlethaler, Écriture et pouvoir à l'aube des temps modernes, Paris, PUF, 2002.

${ }^{11}$ C. Beaune, «L'utilisation politique du mythe des origines troyennes en France à la fin du Moyen Âge", Lectures médiévales de Virgile. Actes du colloque organisé par l'École française de Rome (Rome 25-28 octobre 1982), École Française de Rome, 1985, p. 331-355.

${ }_{12}$ J. Cl. Mühlethaler, Fauvel au pouvoir : lire la satire médiévale, Paris, Champion, 1994. Idem, «Le poète et le prophète. Littérature et politique au $\mathrm{XV}^{\mathrm{e}}$ siècle », Le Moyen Français, 13, 1983, p. 37-57.

${ }^{13}$ Pour l'approche du texte par le biais de son support matériel, je renvoie à la brillante étude de K. Busby, Codex and Context: Reading Old French Texts in Manuscripts, Amsterdam, Rodopi, 2002. En ce qui concerne précisément l'Ovide moralisé, voir aussi l'article de Renate Blumenfeld-Kosinski sur le manuscrit de l'Arsenal qui offre d'intéressants éléments sur la relation texte-image et conçoit le manuscrit comme un mode d'interprétation du texte: $\mathrm{R}$. Blumenfeld-Kosinski, « Illustrations et interprétations dans un manuscrit de l'Ovide Moralisé (Arsenal 5069)», Cahiers de Recherches Médiévales, 9, 2002, p. 71-82. Elle rappelle que parmi les manuscrits illustrés de l'Ovide Moralisé, on distingue deux groupes: trois manuscrits (Rouen, BM 0.4, 453 miniatures ; Paris, Arsenal, 5069, 302 miniatures et Lyon, BM 742) offrent des illustrations des fables et des moralisations et les autres représentent au début de chaque livre des allégories des dieux antiques.
} 
l'éloquence et d'Énée, bénéficiaire des prophéties de Sibylle, pour mettre l'accent sur la nécessité de sapience dans l'ordre du monde. Par ailleurs, à travers l'imaginaire apocalyptique et eschatologique, le texte fait écho aux discours du temps orientés vers un certain engagement politique, notamment le Roman de Fauvel (la satire étant moins évidente toutefois et d'ailleurs réduite par rapport à Ovide lui-même) ${ }^{14}$. L'odyssée depuis Troie et, pour Énée, le voyage vers Rome se dotent d'une signification particulière ${ }^{15}$. Le mythe de fondation renforcé par l'Enéas au XII ${ }^{\mathrm{e}}$ siècle ${ }^{16}$ se double d'une valeur mystico politique: Rome n'est pas seulement le modèle de la royauté, d'une nouvelle dynastie, elle est surtout la cité de Dieu. Cette nouvelle orientation du topos de la translatio imperii s'inscrit dans les évolutions de l'idéologie royale au $\mathrm{XIV}^{\mathrm{e}}$ siècle. C'est ainsi que les relations amoureuses des héros Ulysse, Énée, Romulus se placent dans la glose dans une perspective ecclésiologique (voir la deuxième partie de cet article). Les trois héros principaux de la glose, les trois figures du Christ doivent épouser la sagesse, la Vierge Marie, le port et l'étoile guide de la vie spirituelle (Lavinie, Hersilie) et rejeter la Prostituée de l'Apocalypse (Circé, Ardea). Les livres 12-13-14 de l'Ovide Moralisé se font l'écho d'une idéologie politique fondée dans l'imitation de la cité céleste et offre une vision du couple Christ-Dieu/Vierge comme modèle de l'union mystique et de l'accomplissement de la perfection cosmique (modèle qui s'imposera au $\mathrm{XV}^{\mathrm{e}}$ siècle dans l'idéologie royale ${ }^{17}$ ). La translatio imperii qui suit la chute de Troie prend une coloration politique particulière sous la plume du traducteur d'Ovide au début du XIVe siècle.

\footnotetext{
${ }^{14}$ Gervais de Bus, Le Roman de Fauvel, éd. de A. Langfors, Paris, 1914-1919 (SATF, 63) (voir le manuscrit Paris, BnF, français 146). Les miniatures du manuscrit de Rouen semblent devoir être attribuées au maître du Fauvel. Sur la place moins importante de la satire par rapport à l'hypotexte latin, voir M. Possamaï, op. cit.

${ }_{15}$ Selon l'analyse très fine de M. Possamaï, les livres 12-13-14 abondent en allégories typologiques (typologie christique et ecclésiale), alors que dans les six premiers livres, c'est la tropologie qui domine (interprétation morale chrétienne) et que dans les livres 7 à 11 , la proportion est équivalente entre tropologie et typologie. Le Livre 14 est le livre de l'anagogie (espérance des fins dernières, eschatologie). Au livre 15, on revient à la tropologie avec la grande prédication de Pythagore. M. Possamaï-Perez, op. cit., p. 396-467.

${ }^{16}$ Le Roman d'Eneas, éd. et trad. de A. Petit, Paris, Le Livre de Poche-Lettres Gothiques, 1997. C. Marchello-Nizia, «De l'Énéide à l'Éneas. Les attributs du fondateur », Lectures médiévales de Virgile. Actes du colloque organisé par l'École française de Rome (Rome 2528 octobre 1982), École Française de Rome, 1985, p. 254-265.

${ }^{17}$ Citons les recherches de Lori Walters sur l'idéologie royale chez Christine de Pizan qui se pose comme figure de la Vierge/dame France qui guide le roi vers la rédemption de sa Nation. «Christine de Pizan, l'idéologie royale et la traduction», trad. par R.-Cl. Breitenstein, D'une écriture à l'autre. Les femmes et la traduction sous l'Ancien Régime, éd. J.-Ph. Beaulieu, Ottawa, Presses de l'Université d'Ottawa, 2004, p. 31-52. La pensée de Christine témoigne d'une longue maturation de l'imaginaire politique.
} 


\section{Sagesse et prophétie: le pouvoir de la parole}

\section{Livre 12 : Ulysse. La sagesse contre la force}

Il est assez saisissant de remarquer que toutes les interpolations du livre 12 entretiennent un rapport étroit avec le personnage d'Ulysse, alors que le nom du héros n'apparaît même pas dans le livre correspondant des Métamorphoses d'Ovide. Le roi d'Ithaque est très présent dans le livre 12 de l'Ovide moralisé, tant dans le récit que dans les gloses. Les ajouts par rapport aux Métamorphoses témoignent de la volonté de mettre en évidence l'importance de la figure du diplomate dans le cadre de la guerre, en l'occurrence le rôle joué par Ulysse. L'Ovide moralisé situe le récit dans un contexte narratif plus large que les Métamorphoses et amplifie, grâce notamment au recours à l'Ilias latina ${ }^{18}$, le récit des préparatifs pour la guerre en insistant sur les actes diplomatiques et de médiation pour rassembler l'armée. Après le rapt d'Hélène par Pâris et la décision de Ménélas de partir rechercher son épouse, on trouve le récit de la folie feinte d'Ulysse (Livre 12, v. 1004-1075). Ménélas tente de réquisitionner les souverains de Grèce, dont le roi d'Ithaque. Pour échapper à la guerre, Ulysse feint la folie en semant du sel à la place du blé. L'épisode met en évidence la ruse du personnage, sa subtilité intellectuelle. Ulysse est constamment qualifié de «sage» et de «subtil». L'image du sel semé et l'attribut de sagesse débouchent dans la glose sur une assimilation d'Ulysse l'humanité du péché (incarnée dans l'Ovide moralisé au Christ rédempteur dont la parole-sel de la doctrine- sauve par Troie, Hélène étant l'âme pécheresse) (Livre 12, v. 1205-1316). Ulysse $=$ Christ devient l'acteur principal de la glose dans le livre 12, puisqu'il représente typologiquement le Christ et que la guerre de Troie est l'allégorie de la tentation de l'âme chrétienne par le péché ${ }^{19}$. La tournure prise par la glose est cohérente par rapport à la valorisation d'Ulysse dans la narration. Ulysse devient le personnage principal du Salut en tant qu'allégorie du Verbe incarné.

La valorisation du talent verbal d'Ulysse est renforcée dans l'épisode de l'ambassade d'Ulysse pour réquisitionner le preux Achille. Suite à un avertissement d'oracle, Thétis, mère d'Achille, décide de tenter d'échapper au destin en le cachant dans une abbaye et en le déguisant en fille. C'est Ulysse qui parvient à déjouer la ruse de la déesse et à embrigader Achille pour la guerre contre Troie. C'est également Ulysse qui convainc la mère d'Iphigénie de céder sa fille dont le sacrifice assurera la bonne traversée de l'armée grecque.

Une autre partie interpolée concerne le récit du rapt de Criséis par Agamemnon, la mort de Patrocle, compagnon d'Achille tué par Hector le troyen et la vengeance d'Achille qui tue Hector, enfin, la mort d'Achille. Une place importante est accordée à Achille et à ses armes qui seront transmises à Ulysse dans le Livre 13. Le récit du livre 12 de l'Ovide Moralisé permet de préparer l'épisode de la dispute des armes d'Achille qui débute le livre 13 des Métamorphoses, dispute qui

${ }^{18}$ Récits inédits sur la guerre de Troie. Iliade latine, Éphéméride de la guerre de Troie et Histoire de la destruction de Troie, trad. et commentaire par Gérard Fry, Paris, Belles Lettres, 2004.

${ }^{19}$ M. Possamaï-Perez, «Troie dans l'Ovide moralisé », Entre fiction et histoire: Troie et Rome au Moyen Âge, études recueillies par E. Baumgartner et L. Harf-Lancner, Presses de la Sorbonne Nouvelle, 1997, p. 99-108. 
oppose Ajax, figure de la force et de la colère et Ulysse, figure de l'éloquence et de la sagesse. La description du bouclier d'Achille, reprise de l'Ilias latina, mais largement amplifiée, accorde au savoir une place au sein du métier par excellence de la noblesse $e^{20}$. Les armes du parfait chevalier chrétien sont une métaphore de la somme encyclopédique qui se termine par la description des sept arts libéraux.

L'attribut que se dispute les deux héros grecs est celui du pouvoir et de la rhétorique. Le livre 12 prépare la querelle entre Ulysse et Ajax pour qu'en ressorte plus clairement l'affrontement entre deux types de prince, celui qui fait usage de la force et celui qui est sage. Les deux champs sémantiques sagesse, savoir, éloquence / force, ignorance articulent le débat. Dans le contexte sociopolitique, il ne manque pas de résonner avec subtilité. La conception de la royauté, du gouvernement s'achemine de plus en plus d'une image de roi guerrier à celle de roi instruit, lettré, connaissant les arts libéraux ${ }^{21}$. L'ira dans la bouche du héros a une connotation négative dans la morale politique en vogue surtout à la fin du moyen âge. La colère est un péché, un manque de modération du souverain qui menace de dévier vers la tyrannie ${ }^{22}$.

Les interpolations dues à la traduction du XIV $\mathrm{XV}^{\mathrm{e}}$ siècle construisent un récit soudé et font émerger une figure de héros absente chez Ovide. Les interventions ont une cohérence au niveau de la construction d'un message d'enseignement. La maîtrise de la parole ${ }^{23}$ est une arme prépondérante pour la conduite des affaires

\footnotetext{
${ }^{20}$ À ce sujet je renvoie à mon article : «Si semoit sel en leu d'avaine (OM, XII, v. 1031). De la traduction d'Ovide aux figures d'auteur: Ulysse et le bouclier d'Achille», "Pour Acquerir honneur et pris ». Mélanges G. Di Stefano, éd. Maria Colombo Timelli et Claudio Galderisi, Montréal, CERES, 2004, p. 137-153. Voir aussi M. Possamaï-Perez, «Ulysse ou le triomphe de la mètis », Romans d'Antiquité et littérature du Nord. Mélanges offerts à Aimé Petit, éd. par S. Baudelle-Michels, M.-M. Castellani, P. Logié, E. Poulain-Gautret, Paris, Champion, 2007.

${ }^{21}$ Voir entre autres Philippe Buc, L'Ambiguité du livre. Prince, pouvoir, et peuple dans les commentaires de la Bible au Moyen Âge, Paris, Beauchesne, 1994. Idem, "Exégèse et pouvoir royal », Annales E.S.C., 44/3, 1989, p. 696. On évolue, selon Buc, au XIV ${ }^{\mathrm{e}}$ siècle vers une conception du roi idéal comme un «philosophe » qui règle ses passions par la mesure de l'intellect. Cette évolution est déjà notable au XIIe siècle chez Jean de Salibury, voir J. Krynen, L'Empire du roi. Idées et croyances politique en France XIIIe-XVe siècles, Paris, Gallimard, 1993.

${ }^{22}$ Voir notamment, Jean-Claude Mühlethaler, «De ira et avaritia ou les faiblesses des grands à l'épreuve de l'actualité : des miroirs des princes à l'engagement politique sous Charles VI », Cahiers de recherches médiévales (XIII $\left.{ }^{e}-X V^{e} s\right)$, Lectures et usages d'Ovide (XIII ${ }^{e}-X V^{e}$ siècles), éd. E. Baumgartner, Paris, CNRS, 2002, p. 215-235.

${ }^{23}$ Cette maîtrise de la parole est l'attribut d'Ulysse, héritier d'Hermès, dieu de l'éloquence déjà dans la littérature grecque. Sur la figure de la métis, de la ruse et de l'intelligence et de la parole, voir D. Bouvier, «Le pouvoir de Calypso : à propos d'une poétique odysséenne », La Mythologie et l'Odyssée. Hommage à Gabriel Germain, textes réunis par André Hurst et Françoise Létoublon, Genève, Droz, 2002. Voir aussi Pietro Citati, La Pensée chatoyante. Ulysse et l'Odyssée, trad. de l'italien, Paris, Gallimard, 2004.

Au livre 14 de l'Ovide moralisé, dans le récit de Macareus, Ulysse est associé à l'invention de l'outre dans laquelle sont enfermés les vents (chez Homère, l'outre est due à Éole), voir livre 14, v. 2114-2131). Sur l'importance de la figure de l'invention et la subtilitas, voir: J.
} 
politiques. Alors qu'Ulysse était une figure de traître et de couard sous la plume de Benoît de Sainte-Maure, l'Ovide moralisé lui donne une aura très positive ${ }^{24}$.

\section{Livre 14 : prophétie de Sibylle}

La logique de l'entrelacement dans les Métamorphoses d'Ovide au livre 13 et 14 aboutit à une imbrication des aventures d'Ulysse et d'Énée ${ }^{25}$. L'Ovide Moralisé renforce la comparaison grâce à l'insistance sur la métaphore commune de la nef, notamment par le biais de la glose (les deux héros sont des figures du Christ). Énée incarne un autre type de maîtrise de la parole et du savoir : la prophétie.

Les interpolations dans le livre 14 de l'Ovide moralisé par rapport aux Métamorphoses sont de deux types. Dans un premier temps, elles touchent à la figure de Sibylle ${ }^{26}$. Le rôle de la prophétesse se trouve renforcé dans la mission de fondation du prince. La parole éclairée, le savoir inspiré guide le pouvoir royal d'Énée (voir en particulier les v. 791-971 sur le destin du héros fondateur et les v. 1067-1716, l'énumération des dix sibylles et le songe des cent sénateurs et des neuf soleils).

Dans la visite d'Énée aux enfers où il est accompagné par la Sibylle, le héros reçoit la prophétie sur son lignage. Les Métamorphoses s'attardent sur un dialogue entre Énée et la Sibylle à la fin du parcours qui a trait surtout au personnage de la prophétesse sur le don d'Apollon des mille années de vie. Le destin d'Énée découvert dans les entrailles de la terre n'est qu'évoqué. Or, l'Ovide moralisé apporte des précisions sur l'origine troyenne d'Énée et sur la vision de son père Anchise qui lui révèle son destin dans le Latium : la rencontre de la future épouse Lavinie, la guerre contre Turnus, la naissance du fils Silvius et enfin Romulus qui est du lignage d'Énée et fondateur de Rome :

Romulus, qui de grant renom

Cerquiglini-Toulet, «Cadmus ou Carmenta : réflexion sur le concept d'invention à la fin du Moyen Âge », in What is Literature? France 1100-1600, ed. by François Cornilliat, Ullrich Langer, and Douglas Kelly, Lexington, French Forum, "The Edward C. Armstrong Monographs on medieval Literature", 7, 1993, p. 211-230.

${ }^{24}$ Benoît de Sainte Maure, Le Roman de Troie, éd. et trad. de E. Baumgartner et Fr. Vielliard, Paris, Le Livre de Poche-Lettres Gothiques, 1998. Édition partielle. Pour l'édition complète voir : Le Roman de Troie de Benoît de Sainte-Maure, publiés d'après tous les manuscrits connus par Léopold Constans, Paris, 1904-1912, 6 vol. Cette figure négative d'Ulysse persiste dans les versions en prose du Roman de Troie. Je remercie Luca Barbieri pour cette remarque.

${ }^{25}$ Ulysse est connu au Moyen Âge comme héros de la guerre de Troie. Ce n'est qu'en 1353 que le texte grec d'Homère commence à circuler, d'abord en Italie. Un ambassadeur de Byzance envoie à Pétrarque un manuscrit de l'Iliade et de l'Odyssée. À partir de ce moment les copies se multiplient. Énée, l'Ulysse latin, réalise aussi une odyssée, suivie d'une Iliade (il inverse le schéma Iliade / Odyssée, insistant sur l'acte de reconstruction). Voir R. Martin et J. Gaillard, Les genres littéraires à Rome, t. 1, Paris, 1981.

${ }^{26}$ Sur le personnage de la Sibylle dans l'Ovide moralisé, voir le récent article de A.-M. Babbi, «La Sibylle dans l'Ovide Moralisé», in "Contez me tout». Mélanges de langue et de littérature offerts à Herman Braet, éd. par C. Bel, P. Dumont et F. Willaert, Leuven, Peeters, 2006, p. 423-434. 
Devoit estre et de grant barnage

Et descendroit de son lignage,

Devoit fonder une cité,

Riche et de grant auctorité,

Qui dou mont seroit dame et mestre

Plus que Troie ne soloie estre. (v. 882-888, livre 14)

Énée est l'ancêtre troyen de Romulus, fondateur de Rome. Plus loin dans le même livre, les interpolations viennent renforcer l'édification de l'image d'un roi fondateur, d'une lignée royale. On trouve ainsi ajouté à Ovide dans la traduction moralisée un long récit sur la guerre entre les Romains et les Sabins, la trahison de Tarpeia et l'intervention des Sabines (v. 5911-5994).

Les interpolations des livres 12 et 14 aboutissent au renforcement de trois héros : Ulysse, prince de la parole, Énée, le prince guidé par la prophétie de Sibylle à fonder Rome et Romulus, son descendant. Les trois reçoivent une lecture christique et fonctionnent comme modèles de pouvoir. La nef d'Ulysse embarquée dans une navigation périlleuse représente le Christ incarné dans un corps d'homme pour sauver l'humanité, le Verbe fait chair ou encore l'Église ${ }^{27}$. La nef d'Énée, c'est la nef de Sainte Église qui avance vers le Salut, en d'autres termes dans l'imaginaire médiéval, vers la Jérusalem céleste, vers Rome à fonder, double de la cité de Paradis $^{28}$. Encore une fois l'image est forte et offre des échos par rapport à l'imaginaire politique de la fin du Moyen Âge. La France, point d'aboutissement de la translatio imperii est idéalement le nouveau peuple élu destiné au salut eschatologique, le double imaginaire de la mythique Jérusalem céleste. À la fin du $\mathrm{XIV}^{\mathrm{e}} \mathrm{s}$., siècle avec la vogue des idées millénaristes, on considère d'ailleurs que doit venir un roi de la fin des temps qui reconquerra Jérusalem et annoncera une ère de paix avant la venue du Christ sur la terre ${ }^{29}$. La glose du texte ovidien est cohérente par rapport au discours d'éducation politique qui semble s'insinuer dans le jeu de décalage de la traduction et d'interpolation.

Les héros Ulysse et Énée tels que l'Ovide moralisé les met en scène en relisant et adaptant les Métamorphoses en fonction du système de représentation du public fonctionnent comme des figures exemplaires du pouvoir idéal : un pouvoir basé sur la maîtrise de la parole, sur la sagesse, sur la ruse intellectuelle, sur l'attention portée aux voix de la prophétie, plus que sur la force, et sur la glorification du lignage destiné à fonder une cité que la glose assimile à l'image de

\footnotetext{
${ }^{27}$ Voir entre autres, livre 13, v. 1593-1600: «A la nef Ulixes le sage (...)/ Puis noter convenablement / Toutes les lois communement / Qui doivent assembler à une / Et venir à la nef commune / Qui doit tous mener au rivage / Dou celestial heritage, etc. »

${ }^{28}$ Voir entre autres le livre 14, v. 527-596: allégorie sur la navigation d'Énée qui avance vers le port de la connaissance et arrive chez Didon, Hérésie, port de l'erreur et de l'aveuglement spirituel.

${ }^{29}$ Voir V. Minet-Mahy, Esthétique et pouvoir de l'œuvre allégorique à l'époque de Charles VI. Imaginaires et discours, Paris, Champion, 2006.
} 
la Jérusalem céleste ${ }^{30}$. Leur odyssée maritime est par ailleurs glosée comme une translatio imperii au bout de laquelle il s'agit de fonder une cité de Dieu.

\section{Le manuscrit de Rouen: lettrines et images}

Le texte de l'Ovide moralisé, dans la version du manuscrit de Rouen qu'édite avec plus ou moins de fidélité Cornélis de Boer, semble donner à la translation une coloration de livre d'éducation politique. Cette dimension élargit la perspective plus strictement centrée sur la lecture du texte comme matière de prêche ${ }^{31}$, sans la contredire. Le discours d'enseignement au prince au fil du XIV ${ }^{\mathrm{e}}$ siècle et surtout du $\mathrm{XV}^{\mathrm{e}}$ siècle emprunte la force persuasive de la parole du prédicateur et de l'orateur, n'en prenons pour preuve que le chancelier de l'Université de Paris, Jean Gerson, d'ailleurs amateur d'exempla mythologiques dans les sermons qu'il adresse à la cour ou au roi. Une attention plus poussée aux témoins manuscrits, notamment au manuscrit de Rouen, renforce cette hypothèse d'une réception curiale de l'œuvre comme livre d'éducation. Dans les images et la structuration matérielle du texte, la parole est mise à l'honneur.

\section{Prédicateurs, prophètes, récitants}

La place importante accordée à Ulysse et à Énée, à la parole de sagesse et à la prophétie dès la narration et les interpolations par rapport à Ovide se renforce dans les éléments paratextuels, dans les miniatures ${ }^{32}$ et dans les lettrines. Parmi les 11 miniatures à sujet religieux sur les 33 que compte le livre 12 dans le manuscrit de Rouen, 4 ont directement trait au problème de la parole. Au f. 303 (371) apparaissent les prophètes et les prédicateurs, au f. 304v (373) saint Paul apôtre évangélisateur qui porte le glaive ${ }^{33}$ face sans doute à une figure de saint pénitent (croix). Au folio 314 (385) est représenté Moïse cornu (on y reviendra). De nouveau au f. 316v (389) sont représentés des prophètes. Dans les sujets antiques aussi on peut souligner la présence de l'acte de parole : Nestor qui fait le récit aux folios $308 \mathrm{v}$ (381) et 313v (384), la prophétie de Calcas (f. 314v) et la dispute d'Ulysse et Ajax pour les armes, (f. 324 (395)).

Dans le livre 13, c'est bien sûr la dispute d'Ajax et d'Ulysse qui fait de nouveau l'objet d'une miniature (f. 324/ 398) et surtout, dans les sujets religieux, la figure de Jean-Baptiste, alias Ajax (f. 329v / 399), voir figure 1. Ce dernier est à considérer comme le dernier prophète du Christ (sur l'image et comme dans

\footnotetext{
${ }^{30} \mathrm{La}$ réorganisation de la matière trace une lignée Ulysse/Énée/Romulus. Dans certaine tradition mythologique, Ulysse serait le père de Romos, fondateur de Rome, fils qu'il aurait eu avec Circé.

${ }^{31}$ C'est la thèse développée par M. Possamaï, L'Ovide moralisé. Essais d'interprétation, à la suite de M.-R. Jung et J.-Y. Tilliette.

${ }^{32}$ Voir en annexe le tableau des miniatures dans les livres 12 à 14 du manuscrit de Rouen.

${ }^{33}$ Sur l'image de la Parole, du Verbe comme glaive dans la Bible, voir entre autres : Matth. 10,32; Apoc. 19,15. Dans le livre 13, v. 1212, la parole de Dieu est qualifiée de «dart trenchant » qui combat pour la victoire de l'Église. Voir également la prédication comme glaive, livre 15, v. 2728 ou comme flèche : livre 15, v. 4411-4433 (figure du Sagittaire).
} 
l'iconographie traditionnelle du saint, il porte dans la main un agneau) ${ }^{34}$. Le thème iconographique de la parole et de la prophétie se double de celui du martyre. Au f. $331 v$ (401), la miniature représente le décollement de Jean-Baptiste. Or, dans le livre 14, les sujets religieux au nombre de 8 sur 33 images font alterner les figures de prophétie et de prédication d'une part et les persécutions de l'Église de l'autre.

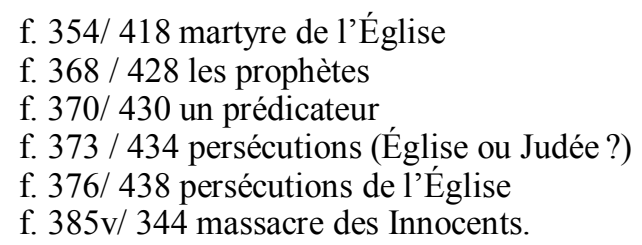

Un des messages véhiculés par l'image est celui de l'urgence et de la puissance de la parole devant le péril de la mort et de la fin des temps. La figure du prédicateur s'impose avec force. Par ailleurs, à la fin du XIV siècle, la figure de la tyrannie apparaît représentée dans des manuscrits de traduction d'Aristote par Oresme accompagnée des scènes de tortures et de supplices qui font échos aux persécutions de l'Ovide Moralisé ${ }^{35}$.

\section{Le futur prophétique}

Les prophéties de Sibylle à Énée, on l'a vu, font l'objet d'amplifications importantes par rapport au texte ovidien. La fonction indicative des lettrines dans le cadre de l'exposition sur le songe des cents sénateurs qui ont vu neuf soleils est particulièrement nette. Sibylle et Énée montent sur le mont Apennin et la prophétesse expose la signification du songe qui touche à l'histoire du Salut, à la venue du Christ, à la succession des royaumes depuis sa mort et à la fin des temps, la venue de l'Antéchrist et le Jugement dernier. L'explication se fait entièrement sur le mode du futur prophétique et se termine en apothéose rhétorique par un passage

\footnotetext{
${ }^{34}$ La fable oppose deux personnages qui plaident devant l'assemblée des Grecs pour recevoir les armes d'Achille. Les paroles d'Ajax sont marquées par la colère, celle d'Ulysse par la sagesse. Or, Jean-Baptiste, considéré comme un prophète, l'héritier d'Élie, voire même le Messie attendu, est connu pour la véhémence de son prêche et la dureté de la vie ascétique au désert. Le glossateur tire parti d'une rivalité potentielle entre Jean-Baptiste et le Christ, que démentent les Évangiles synoptiques (voir Luc 3, 15-27). La glose transforme le duel en rivalité de deux modèles de paroles.

${ }^{35}$ Claire Richter Sherman, Imaging Aristotle. Verbal and Visual Representation in Fourteenth Century France, Berkeley, University of California Press, 1995, pl. 7: Les politiques d'Aristote, ms. Bruxelles, KBR, 11202-202. Le manuscrit a été réalisé à Paris en 1376, au moins un demi siècle après celui de Rouen. Au fol. IV la miniature pleine page représente un tableau en trois parties : au dessus Tyrannie: un personnage couronné est entouré de deux scènes d'atrocités (tortures et décapitation), au deuxième étage, Olygarchie où l'on retrouve également des tortures et décollation, et enfin des scènes de supplices autour de Democracie. Il y a lieu de se demander si la tyrannie est souvent liée dans l'iconographie et l'imaginaire au martyre et par ailleurs à quels faits de persécution l'Ovide moralisé pourrait faire référence dans l'actualité de son temps.
} 
en alexandrins construit sur une alternance particulière de strophes (livre 14, v. 1689-1716) : 3 quatrains d'alexandrins monorimes, ensuite un distique, un tercet, un quatrain et trois distiques (chaque strophe est monorime). Le passage remarquable par le changement de mètre et de versification est rehaussé par le paratexte : chaque début de strophe (changement de rime) est signalé au f. 360v du manuscrit de Rouen par une nouvelle lettrine (SLLLCLLLQ, ensemble aussi harmonieux esthétiquement), (voir figure 3). En tout on compte 10 "paragraphes ». Les dix éléments de la prophétie sur l'apocalypse et sur le jugement dernier font écho aux dix commandements mosaïques indubitablement. L'Antéchrist incite à l'idolâtrie et à l'aveuglement spirituel, inverse la sagesse de Moïse. Le futur prophétique fait pendant au futur du commandement. Il signifie l'urgence de l'injonction et du discours didactique.

La séquence des dix prophéties soulignées par les lettrines se termine par une enluminure représentant Sibylle et Énée dans le temple offrant le sacrifice d'un agneau (figure du Christ ?). La rubrique de la table initiale du manuscrit donne l'explication : "Comment Sebille conte à Eneas ce qui li est à avenir et comment Eneas se part de Sebille et fait sacrifices aus dex quant il est eschapez de ses mains et des tourmens d'enfer ou il avoit esté. » (f. 14). Sibylle est aussi représentée au f. 355 (420), introduisant Énée dans la gueule d'enfer et au f. $357(421)^{36}$ face à trois têtes couronnées (des sénateurs, ou la Trinité dont il vient d'être question dans le vers qui précède).

\section{Moïse, le prince éclairé}

La structuration matérielle de la prophétie de Sibylle sur le modèle numérique du décalogue donne à la prophétie une autorité et fait émerger en filigrane une figure de la parole et de la musique, Moïse, importante dans l'imaginaire politique du XIV siècle $^{37}$. Dans le Roman de Fauvel, le narrateur prend pour modèle Moïse, guide spirituel d'une société en proie au dévoiement et adorant le veau d'or (le monde terrestre et ses richesses). Moïse est figure de prêtre et de roi $^{38}$, il incarne la figure de la sagesse divine, du verbe révélé qui guide la bonne conduite spirituelle et politique. Moïse est aussi parfois tenu au Moyen Âge, et notamment au XIV ${ }^{\mathrm{e}}$ siècle, par Évrart de Conty dans les Échecs amoureux moralisés, pour l'inventeur de la musique ${ }^{39}$. Une étymologie du mot musique l'associe à Moïse, celui qui est né des eaux. Or, une des métaphores privilégiées de la prédication dans l'Ovide moralisé est celle de la musique qui doit établir l'harmonie universelle du cosmos à l'image du corps-cithare du $\mathrm{Christ}^{40}$.

\footnotetext{
${ }^{36}$ Aventure glosée comme la descente du Christ aux enfers pour sauver les élus.

${ }^{37}$ Rappelons que la cithare décacorde est souvent rapprochée des dix commandements de Moïse et du corps du Christ résonnant pour le salut de l'humanité (voir V. Minet-Mahy, Esthétique et pouvoir de l'œuvre allégorique, op. cit., p. 66-98.)

${ }^{38}$ Voir J. Cl. Mühlethaler, Fauvel au pouvoir, op. cit. On retrouve Moïse, figure de Charles VI, sous la plume de Philippe de Mézières dans le Songe du Viel Pelerin.

39 À ce sujet, voir l'étude de J.-M. Fritz, Paysages sonores du moyen Âge. Le versant épistémologique, Paris, Champion, 2000, p. 90-106.

${ }^{40} \mathrm{Je}$ renvoie à mon analyse dans Esthétique et pouvoir de l'œuvre allégorique à l'époque de Charles VI, p. 98-145, sur le Livre 10 (Orphée). Dans le Livre 14, c'est la nymphe Canens qui
} 
Moïse apparaît dans le programme iconographique du manuscrit de Rouen, dans le Livre 9 au f. 241v (illustration de l'allégorie de la fable de Byblis ${ }^{41}$ ) et dans le livre 12, f. 314 : il reçoit dans les deux cas les tables de la Loi et porte des cornes. Que signifie l'image de Moïse cornu ? À trois endroits dans l'Exode : Ex. 34, 29-30 et $35^{42}$, Moïse est décrit, après la seconde alliance, redescendant de la montagne où il a «vu»Yahvé ${ }^{43}$. Le texte hébreu utilise le terme karan pour qualifier le visage transformé de Moïse, terme qui signifierait 'resplendir', mais proche d'un autre mot dont le sens signifie 'cornu'. D'où une erreur de traduction de saint Jérôme dans la Vulgate. La face de Moïse, après avoir eu la vision divine devient enluminée, rayonnante, mais dans le texte de la Vulgate, cornue. L'image de la corne est associée à celle de la puissance (voir la corne d'abondance).

La miniature de Moïse cornu dans le livre 12 introduit la glose sur le récit de Nestor, au vers 3139 («Historial sens puet avoir»), mais en rapport avec l'interprétation chrétienne et typologique qui débute quelques vers plus loin: v. 3161 «Metre i puis autre entendement $»^{44}$. Nestor, héros grec de la guerre de Troie, dans le livre XII des Métamorphoses fait le récit du combat des Lapithes et des Centaures auquel il a participé. Intervient ensuite Tlépolémus qui rappelle les mésaventures de Nestor et de ses onze frères avec son père Hercule. Les onze frères de Nestor ont été tués par Hercule, le dernier s'est métamorphosé en aigle et seul Nestor y échappa. L'allusion au rôle d'Hercule (v. 3035-3138) dans le destin de Nestor donne lieu à deux gloses allégoriques. Hercule est Dieu qui défait le diable et qui détruit les idoles des Israélites, le veau d'or, tandis que Nestor signifie Israël, l'aveuglement des juifs idolâtres :

Cil destruist les filz d'Israël

Qui firent le doré vaël,

Que li ydolatre aorerent,

Et qui au desert Dieu tempterent (v. 3171-3174).

est allégorisée comme la prédication, voir livre 14, v. 3338 et sq. Canens est d'ailleurs représentée dans le manuscrit de Rouen en train de charmer les oiseaux par son chant, f. 366v / 427. Dans un manuscrit illustré par l'atelier du maître de Fauvel, Paris, BnF 156, une Bible historiale de Guiard de Moulins, on trouve en relation avec les épisodes de la révélation divine à Moïse, une lettrine historiée qui représente un personnage tenant une cithare décacorde, f. $81 \mathrm{v}$. Le manuscrit est consultable sur Mandragore.

${ }^{41}$ Byblis amoureuse de son frère est allégorisée comme la divine sapience, comme l'amour de la Sagesse pour la créature. La lettre qu'elle écrit à son frère représente les tables de la loi que Moïse, figure de sapience donc, livre aux Israélites (Livre 9, 1997-2530, Byblis est changée en fontaine, la glose se situe aux v. 2531-2762).

${ }^{42}$ Ex, 34,29 : «Cum que descenderet Moses de monte Sinai tenebat duas tabulas testimonii et ignorabat quod cornuta esset facies sua ex consortio sermonis Dei. »

${ }^{43}$ E. G. Suhr, «The Horned Moses », Folklore, 74/2, 1963, p. 387-395.

${ }^{44}$ La rubrique 385 au f. 13 dans la table située au début du manuscrit de Rouen dit ceci: « Ci dist l'alegorie que Hercules senefie Dieu le tresfort qui vainqui le deable et fait mencion des juis qui firent le veel d'or au temps de Moïse le cornu ». 
La miniature indique avant que ne s'entame la glose historique, l'importance de la glose allégorique. Elle met l'accent sur un stéréotype qui oppose la révélation divine à l'idolâtrie ${ }^{45}$.

Sagesse, pouvoir de la parole et de la prophétie contre le péril de la fin des temps, prince éclairé contre tyrans aveugles: l'iconographie renforce le message d'enseignement politique.

\section{Imaginaire apocalyptique et eschatologique \\ Énée et Lavinie: arriver au port du Salut}

La Sibylle prophétesse et l'interpolation du songe des cent sénateurs placent d'emblée dans une rhétorique et dans un imaginaire apocalyptique. C'est sur celui-ci que je voudrais m'attarder, essentiellement à travers les gloses, après avoir mis en évidence le thème de la parole et de la sagesse dans la conduite des héros, figures de princes. L'arrivée d'Énée sur la terre de la cité à fonder, Rome, la navigation maritime qui précède se placent aussi dans cette perspective eschatologique. La nef d'Énée est le bateau de Sainte Église, image très répandue et spécialement dans les textes de Guillaume de Digulleville pratiquement contemporains. Elle avance vers le port du Salut qui est en même temps la ville à fonder, donc, la cité céleste. Ainsi, Turnus qui prétend aussi épouser Lavinie et s'emparer de l'héritage de Latinus se trouve-t-il assimilé à l'Antéchrist. La guerre entre Énée et Turnus devient allégorie de la bataille de la fin des temps entre l'Antéchrist et le sauveur de l'humanité pour se joindre à l'épouse céleste, la Vierge, antagoniste de la Prostituée de l'Apocalypse (Livre 14, v. 3625 et sq.) L'imaginaire apocalyptique est à son comble dans la traduction, le commentaire allégorique et le paratexte de l'épisode, au livre 14, de l'incendie de la nef d'Énée par Turnus et de sa transformation, par la déesse Cybèle, en Naïades, puis de l'incendie de la ville de Turnus, Ardea. La nef d'Énée avait été construite avec des pins consacrés à Cybèle. Lorsque la déesse sent que le navire est en feu, elle se précipite au secours d'Énée dans son char tiré par des lions, trompettes sonnant (v. 4238 et sq: «Aussi come arains selt soner, / Si tint une longue buisine, / De buis, dont el corne et buisine, / Et vait par l'air en char volant»), provoque une tempête de pluie pour stopper l'incendie et transforme les bateaux de la flotte en nymphes (OM, livre 14, v. 4208 et sq). Au folio 375 du manuscrit de Rouen, la déesse surgit des cieux, couronnée et sonnant de la «busine», voir figure 4. L'élément iconographique ne trahit pas le texte d'Ovide, mais joue sur une redondance isotopique avec l'imaginaire apocalyptique des trompettes annonçant la fin des temps et rappelle l'instrument favori des anges musiciens sur les scènes de jugements derniers. L'accentuation est d'autant plus

${ }^{45}$ Pour plus de détails sur la figure de Moïse et sur les images associées au bovidé dans l'Ovide moralisé, voir: V. Minet-Mahy, « De la poétique des métamorphoses à la politique de la translatio dans l'Ovide moralisé », Les enjeux des récits de fiction de métamorphose dans l'Ovide moralisé, éd. par M. Possamaï-Perez, Paris, Champion (essais sur le Moyen Âge), à paraître. Je signale que dans un manuscrit illustré par l'atelier du maître de Fauvel, le ms. Paris, BnF, français 156, une Bible Historiale de Guiard de Moulins, Moïse est représenté pas moins de neuf fois, toujours portant les cornes : f. 49 , f. $51 \mathrm{v}$, f. $59 \mathrm{v}$, f. 61 , f. 67 , f. 71 , f. $72 \mathrm{v}$, f. 89, f. 105. (Images consultables sur le site http://mandragore.bnf.fr/html/accueil.html). 
importante que l'attribut principal de la déesse, le char et les lions n'apparait pas sur la miniature. Après la métamorphose de la flotte d'Énée en Naïades vient l'incendie de la ville d'Ardea et sa métamorphose en oiseau (OM, Livre 14, v. 4308 et sq). La glose allégorique renforce le schéma apocalyptique (v. 4367 et sq). Dans un premier temps, le glossateur assimile Cybèle à la Vierge, la mère du Christ qui sauve la nef de Sainte Église (v. 4417). Marie, gardienne de l'Église joue de la «buisine» et soumet les éléments à la musique pour le salut (image de l'harmonie cosmique de la Vierge, on y reviendra). L'eau engendrée pour inonder l'incendie représente le baptême, la purification. C'est donc la Vierge qui vient à bout de l'Antéchrist Turnus. La ville de celui-ci, Ardea est assimilée à Babylone, v. 4520: "C'est Babiloine, l'orgueilleuse, / La citez de confusion ». Après la défaite de Turnus et des forces du mal qu'il représente, peuvent enfin avoir lieu les épousailles attendues : Énée/Lavinie ; la Vierge/ L’Église/Le Christ. Dans le manuscrit de Rouen au f. 377v est illustré le mariage de Lavinie et Énée.

\section{Hersilie et Romulus: fonder la cité céleste, Rome}

Les amours de Romulus, descendant d'Énée et fondateur de Rome, et de Hersilie poursuivent sur la métaphore des épousailles mystiques dans un sens ecclésiologique et politique. Romulus, fils de l'accouplement d'Ylie et de Mars est le Christ, fils de la Vierge Marie (v. 6052). L'abandon des jumeaux Remus et Romulus sur les eaux du Tibre par Amulius, leur oncle, roi usurpateur est lue comme une allégorie du massacre des Innocents par Hérode et la restauration du roi Numitor par Romulus contre Amulius comme la restauration du salut contre l'œuvre du diable. Romulus bâtisseur de Rome devient le fondateur de la cité de Sainte Église : v. 6089: "C'est cil qui regne et regnera, / Et ses roiaumes durera / En glorieuse eternité, / C'est cil qui basti la cité / de Sainte Yglise et fermement / La fonda sur fort fondement, / Qui ore est dame et chiez dou monde... ».

Dans ce schéma, l'interprétation conduit à l'identification de Rome fondée par Romulus avec la ville du Salut, redressant Troie, figure de la chute. Les héros antiques, modèles de princes et leur action politique sont intégrés dans la perspective de l'histoire sainte. L'enjeu pour Énée parti de Troie n'est plus seulement de fonder un royaume, une dynastie issue de l'amour du couple, mais une cité de Dieu. Avant d'arriver au port de la connaissance, auprès de Lavinie, il doit éviter Hérésie, Didon, reine de Carthage (Livre 14, v. 540). Le modèle de pouvoir au XIV ${ }^{\mathrm{e}}$ siècle renforce son aura et son autorité par l'emprunt à la sphère religieuse des attributs du pouvoir. La royauté très chrétienne s'affirme comme pouvoir temporel et spirituel qui assure le salut de la nation et idéalement calque la gestion de la cité terrestre sur la cité céleste. La traduction des Métamorphoses va dans ce sens. Après Énée vient Romulus qui bâtit la ville de Dieu. Hersilie offre une nouvelle occasion de solliciter le mythe des noces mystiques, figure des épousailles du roi et de sa Nation, de l'Église et de son peuple ${ }^{46}$. Dans le livre 14 des Métamorphoses, Romulus est déifié par Mars son père. En terme allégorique, c'est la résurrection du Christ. Hersilie épouse du roi des Romains se lamente sur la perte de son mari (comme l'Église pleure la perte de son époux). Elle est déifiée par Iris et transformée en étoile. Dans la première glose (v. 6595-6660) Hersilie symbolise la Vierge Marie ou l’Église

${ }^{46} \mathrm{R}$. Descimon, «Les fonctions de la métaphore du mariage politique du roi et de la république (France, $\mathrm{XV}^{\mathrm{e}}-\mathrm{XVIII}{ }^{\mathrm{e}}$ siècles) », Annales E.S.C., 6, 1992, p. 1127-1147. 
épouse du Christ éplorée à la mort de son fils/époux, puis les trois Marie à qui le Christ apparaît ressuscité (voir aussi la miniature Rouen, f. 389 : le Christ ressuscité apparaît aux trois Marie). Marie/ Sainte Église/Hersilie est l'étoile qui illumine le monde en annonçant la résurrection du Christ et qui par l'assomption est assise à la droite du père dans les cieux et couronnée.

La deuxième glose (v. 6660-6716) prolonge la première en identifiant plus clairement encore Hersilie à la Vierge et en offrant une synthèse des métaphores mariales directrices dans la gestion de l'imaginaire eschatologique dans les livres 12 à 14, métaphores qui jouent un rôle dans l'économie du discours politique :

- Elle est l'épouse du Christ, l'Église, la reine du monde.

- Elle est « la game de Judee et de Gentilise ». La métaphore de l'accord musical est déterminante sur le plan de l'imaginaire de la Cité de Dieu (voir saint Augustin, livre 17). Rappelons que Cybèle sauve Énée par le son de sa buisine et que Canens, figure d'harmonie, séduit Picus (Christ) par son chant.

- «Elle est estoile et pors de mer / Qui tuit mortel doivent amer». L'épouse se situe au bout du voyage maritime et la fondation de la cité coïncide avec le mariage (mystique). Déjà dans le Livre 12, dans la glose sur la mort de Cygnus, la Vierge est le port du salut: v. 1935-1936 «Ains que Diex incarnation preïst en la vierge Marie / Qui est pors de joieuse vie ».

En somme la boucle est bouclée. En cheminant sur la nef de l'Église/de l'État, Ulysse/Énée figures de prince accomplissent le voyage qui assure le Salut de l'humanité/du peuple et connaissent la vérité l'amour de la Sagesse. Au bout du chemin se situe l'espoir d'une cité à fonder, une cité du Salut et une cité où a lieu l'amour entre les deux éléments de la nation : le roi et l'Église/Vierge (et bientôt dans l'imaginaire royale, la France identifiée à Marie). Ulysse embarqué sur son navire figure aussi l'incarnation du Christ.

Au livre 14, v. 2024-2026, Ulysse est: «la sapience divine, / Qui vint en ceste mortel vie / Ou vessiau de charnel navie...». Dans son Odyssée, il connaît aussi des aventures amoureuses relues dans le schéma des épousailles mystiques. Circé l'enchanteresse n'est autre que la Prostituée de l'Apocalypse de Jean (v. 25632674):

Cyrcé puet noter la roïne,

L'orde pute de male orine,

Mere d'abhomination,

Dont Sains Jehans fet mencion

Ou livre de l'Apocalipse.

C'est l'orde, maleoite lisse

Qui o soi fait avoultroier

Les rois de terre et forsvoier

Dou droit chemin de verité.

C'est cele qui de vanité

Et de sa prostitucion

Et d'orde abhominacion

Et dou delit de son putage

Fait la poison et le bevrage

Dont les princes dou monde enyvre. 


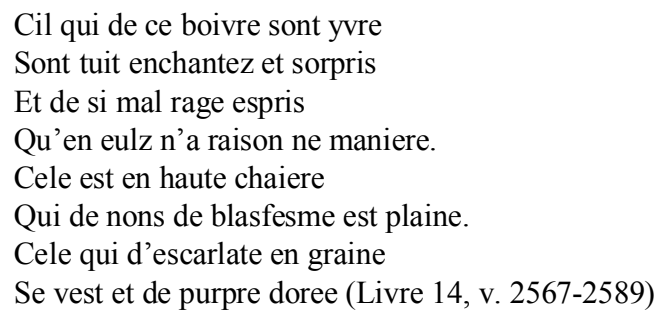

Circé enivre les princes terrestres du poison de l'idolâtrie (v. 2605 : «C'est fausse Ydolatrie») et provoque la folie, la rage, l'orgueil, la gloutonnie: tous les péchés que doivent éviter les rois. Comme le veau d'or, elle aveugle les tyrans du monde «Et seignorioit ses derois / Sus dus, sor princes et sor rois », v. 2607-2608. Ulysse, sagesse divine vient sauver le monde de l'égarement idolâtre en épousant le peuple des Gentils (v. 2616). Il évite la folie tyrannique par son amour de la Sagesse. Le poison de Circé est le vin de l'ignorance qui cause les vices (métamorphose en porcs des compagnons d'Ulysse) et dont seul l'amour du savoir (sapience) peut sauver.

La narration de la métamorphose de Picus en pic vert par Circé alors que le roi refuse les avances de l'enchanteresse ancre encore plus solidement l'image du couple Christ/Église-Sagesse et semble aussi actualiser la problématique politique. Picus, roi du Latium est l'époux de la nymphe Canens (Livre 14, v. 2705 et sq). Un jour qu'il est à la chasse, Circé le prie d'amour et lui la refuse, subissant l'enchantement de la sorcière. La glose chrétienne est importante sur ce double d'Ulysse résistant aux avances de la prostituée de l'Apocalypse. Il est figure des prophètes et des apôtres qui se joignent à la Sainte Prédication (Canens, figure du chant est représentée dans la miniature du f. 366v/ 427 en train de séduire les oiseaux et les bêtes sauvages par son chant, à la manière d'Orphée. Elle porte l'attribut royal de la couronne). Il est figure du roi des rois qui a pris chair humaine. Enfin, il représente les prédicateurs qui incitent à la recherche de Dieu.

\section{La réception de l'Ovide moralisé et de son message politique}

L'Ovide moralisé véhicule un sens politique. Comment celui-ci a-t-il été perçu? Il conviendrait de cibler plus systématiquement les lieux d'émergence d'une réflexion sur le pouvoir et d'observer leur réception. En tous cas, l'aura acquise par Ulysse, héros effacé ou décrié jusqu'ici dans les lettres françaises, "renaissant» dans l'Ovide moralisé, ne fait que se confirmer en tant que modèle de sagesse politique. Dans le programme iconographique des livres 12-13-14 du manuscrit de Lyon, qui ne compte que sept images, Ulysse apparaît deux fois :

- 198v Ménélas reçoit Paris

- 203 Paris enlève Hélène

-205 Folie feinte par Ulysse pour ne pas embarquer dans la flotte grecque $-222 \mathrm{v}$ Mort d'Achille

Livre 13

$-224 \mathrm{v}$ Ulysse reçoit les armes d'Achille (en tête de livre, seule miniature) 


\section{Livre 14}

- f. 241v Glaucus et Circé

- f. 243v suicide de Didon.

Les scènes de bataille lors de la guerre de Troie, la mort d'Hector et les déplorations sur sa sépulture, et même le héros Énée ont disparu des préoccupations du miniaturiste. Signe qu'Ulysse est la figure de la sagesse et de la parole politique qui convient à l'imaginaire du pouvoir à la fin du XIV siècle ?

Cette figure d'Ulysse liée à l'invention, à la parole et à leur importance politique se retrouve dans l'Epistre Othea de Christine de Pizan (1401 ${ }^{47}$. L'Epistre Othea se présente comme une lettre adressée de la déesse Othea au jeune Hector pour lui enseigner la bonne conduite chevaleresque à travers 100 exemples mythologiques (destinataire, Charles VI ou Henri IV). Chaque exemple est composé d'une illustration, d'un quatrain d'octosyllabes, et de deux gloses en prose. La première est une glose morale et se termine par une citation, la seconde est une allégorie chrétienne qui se termine par un passage de la Bible. Quatre exemples impliquent la figure d'Ulysse. C'est la quatre-vingt troisième qui nous retiendra.

Tu te peus bien esbatre aux gieux

Ulixés, en temps et en lieux,

Car ilz sont soubtilz et honnestes,

En temps de treves et de festes.

glose

Ulixés fu un baron de Grece de grant soubtilleté ; et ou temps du lonc siege devant Troye, qui .x. ans dura, tendis que treves estoient, trouvoit gieux soubtilz et moult beaulx pour esbatre les chevaliers tant qu'ilz estoient a sejour. Et dient aucuns que il trouva le gieu des eschés et de telz semblables. Pour ce dit au bon chevalier que en temps deu se peut bien a tieulx gieux esbatre. Et dit Solin : «Toute chose soubtille et honneste est loyalle a faire. »

\section{Allegorie}

Les gieux Ulixés peuent estre entendus que, quant l'esperit chevalereux sera lassé d'aourer et d'estre en contemplacion, il pourra bien soy esbatre a lire les Saintes Escriptures ; car comme dit saint Jerome es Morales : «La Sainte Escripture si est proposee es yeulx de nostre cuer comme un mirouer, a ce que nous y veons l'enterine face de nostre ame. La pouons nous veoir nostre bel, la pouons nous veoir nostre lait, la pouons nous veoir combien nous prouffitons et combien nous sommes loings de prouffiter. A ce propos dit nostre Seigneur en l'Euvangile : «Scrutamini scripturas in quibus putatis vitam eternam habere » Johannis quinto capitulo.

\footnotetext{
${ }^{47}$ Christine de Pizan, Episte Othea, éd. de G. Parussa, Genève, Droz, 1999.
} 
Comme dans l'Ovide moralisé, la subtilité est attribuée à Ulysse. Par son talent d'inventeur, ce dernier apporte du loisir dans l'armée grecque ${ }^{48}$, comme la poésie, les récits d'histoire plaisent aux lecteurs et les récréent en même temps qu'ils re-créent, régénèrent l'esprit qui doit se libérer de préoccupations journalières pour assurer son équilibre. L'allégorie chrétienne redouble la figure de l'invention par celle de la Parole. Jouer au jeu d'échecs revient à lire les Saintes Écritures. Celles-ci sont un miroir pour l'âme qui permet de se connaître, de reconnaître le bien du mal. Plus encore qu'un inventeur, Ulysse est comparable au Christ, au Verbe incarné qui apporte la vie éternelle, comme l'indique la citation de saint Paul. La proximité d'Ulysse et du Verbe est une donne déjà forte dans la moralisation d'Ovide au début $\mathrm{du} \mathrm{XIV}^{\mathrm{e}}$ siècle. Ulysse incarne la sagesse divine.

Figure d'inventeur, figure de poète, Ulysse renaît à la fin du Moyen Âge dans le discours littéraire et politique, sans doute sous l'influence de l'Ovide moralisé. L'art oratoire et la sagesse chrétienne sont les guides de la vie politique ${ }^{49}$. Si on n'a pas encore clairement identifié d'influence de l'Ovide moralisé sur la prédication stricto sensu, par contre, on sait quelle importance la traduction des Métamorphoses en vers a eu dans l'œuvre de poètes comme Guillaume de Machaut, Jean Froissart, Christine de Pizan, Eustache Deschamps.

\section{Le message politique: bilan et perspective}

Le devenir de la figure du roi d'Ithaque dans la tradition manuscrite de l'Ovide moralisé et dans des textes d'éducation chevaleresque et d'enseignement princier tel que l'Othea porte témoignage de la réception d'un message politique véhiculé dans l'Ovide moralisé, particulièrement dans le manuscrit de Rouen. Ulysse et Énée, les héros d'odyssées maritimes dans les livres 12 à 14 de l'Ovide moralisé, accomplissent une translatio imperii. La mission dont ils sont investis, eux ou leurs héritiers, consiste certes à fonder une ville, un royaume, mais surtout un lieu sacré : une cité de Dieu, Rome. En outre, la figure eschatologique de la cité céleste affleure continuellement, accompagnée de l'imaginaire sacré de l'union mystique du Christ et de la Sagesse sous le voile des personnages antiques.

L'Ovide moralisé allégorise Troie comme lieu de la chute, de la damnation de l'âme. Après Troie, il faut ramener l'humanité au Salut. Or le roi de France se présente comme un descendant des Troyens et en même temps s'impose de plus en plus au XIV $\mathrm{XI}^{\mathrm{e}}$ siècle comme le roi très chrétien au pouvoir thaumaturge, celui qui doit guider son peuple par sa sapience. Ce nouveau Moïse ne trouve-t-il pas dans les personnages d'Ulysse, d'Énée et de Romulus, les époux de la sagesse, des émules? Mais la cité de Dieu, Rome n'est pas Paris. De l'une à l'autre ville il y a un pas...

48 Denis Foulechat, Le Policratique de Jean de Salisbury (1372), livre I-III, éd. de Ch. Brucker, Genève, Droz, 1994, p. 112. Au Livre I, 4, 41, Ulysse qui résiste à Circé est figure de sagesse.

«Et aucuns sont qui mectent avant celui art, ou quel on lit que Ulixes joua, pour ce que en aucune maniere elle semble aguiser l'enging par grant pensee et lonc hantement. Mais elle me semble de tant plus damagable et perdue comme il n'est rien plus maleureus ne plus mescheant que se en grant labour pou ou neent tu proffites. » Livre I, V, 18.

${ }^{49}$ Pour d'autres témoignages du XV ${ }^{\mathrm{e}}$ siècle de la fortune d'Ulysse, prince de l'éloquence, voir notre article «Si semoit sel en leu d'avaine », art. cit. 
Il convient en outre de remarquer combien l'Ovide moralisé encense, en même temps que la ville de Rome, le pape. Dans le livre 15, l'éminence de celui-ci est proclamée avec force. Numa qui reçoit l'enseignement du sage Pythagore est ramené dans la glose à une figure de la papauté. Le glossateur se livre à une critique des «faux empereurs» (v. 6268). Le pape doit être le chef spirituel du monde: v. 7387 : «Et le pape paisiblement / Puisse avoir le governement / De tous, etc. » Dans le contexte politique, l'affirmation est «grave». On connaît les démêlés de Philippe le Bel avec Boniface VIII et l'installation du pape en Avignon dès 1314. Ailleurs, les attaques contre les évêques sont nombreuses... Notre auteur prend, par rapport à l'Église, des positions qu'il conviendrait de recenser systématiquement et de resituer dans leur contexte. Il n'hésite pas non plus à dénoncer les cruautés des tyrans contre le «menu peuple»: (Livre 15, v. 2852) et de rappeler l'amour du Christ pour ce même «menu peuple» (Livre 15, v. 6882).

Ainsi, l'Ovide moralisé, en particulier dans sa version la plus ancienne conservée, le manuscrit de Rouen, se présente-t-il comme une berceau d'idées politiques, une mine de message, pour la bonne conduite du gouvernement de l'âme et du peuple. Mais l'ambiguïté du propos ne permet pas de conclure fermement à l'appartenance du texte au genre du miroir des princes ${ }^{50}$. Le texte enseigne la sagesse nécessaire au pouvoir, une sagesse qui n'a d'égal que le Christ (et son épouse, la Vierge). Il présente les germes d'une idéologie royale en voie d'affirmation et dont le règne de Charles $\mathrm{V}$ assurera l'aura.

À l'issue de cette recherche, il convient de se situer dans le champ des perspectives actuelles sur l'Ovide Moralisé. L'hypothèse d'un texte lié à la pratique du sermon se défend grâce à une série de preuves probantes ${ }^{51}$. On se permettra de soulever néanmoins une contradiction, une faille dans l'édifice de lecture échafaudé brillamment par Marylène Possamaï à la suite de M.-R. Jung et J.-Y. Tilliette. Si M. Possamaï montre très bien la cohérence d'ensemble de l'œuvre, le lien élaboré entre la traduction et la glose; le travail de progression entre les différents types de lecture allégorique ${ }^{52}$; l'évolution aussi d'un livre à l'autre qui suppose une progression du lecteur ${ }^{53}$. Cette vision des choses suppose une lecture linéaire de

\footnotetext{
${ }^{50}$ Le lectorat ou l'auditoire dans le livre 15 va clairement dans le sens d'un public de clercs universitaires : v. 7473-75: «Je pri tous les lectors/ Tous les maistres, tous les rectors / qui orront et lirons ce dit». L'Université de Paris joue un rôle politique non négligeable qui tend à s'affirmer au long du XIV ${ }^{\mathrm{e}}$ siècle, elle deviendra sous la plume de Jean Gerson la fille du roi, voir notamment le sermon «Pax hominibus bonae voluntatis», sermon prononcé devant le roi le 18 décembre 1409 en vue de la paix et de l'union fait l'apologie de la réconciliation de l'Église dans le contexte troublé du Schisme. Sermon 365, éd. Glorieux, t. VII*, p. 765 766. Gerson est le porte-parole de l'Université, également dans le sermon célèbre «Vivat rex » prononcé en 1405 devant la cour.

${ }^{51}$ M. Possamaï, op. cit.

52 Notamment la démonstration convaincante sur les «relais sensibles» et le saut herméneutique qui s'inspire des travaux de G. Dahan et qui montre la dynamique qui se met en place entre les différents niveaux de lecture.

${ }^{53}$ Les relais sensibles (lectures historiques et naturalistes) tendent à se faire plus rares au fil des livres, de même que les formules de transition. Ce dispositif tend à montrer, non pas un
} 
l'Ovide Moralisé, un cheminement du lecteur du livre 1 au livre 15. A contrario, l'idée d'une matière à sermon indique plutôt une lecture sélective, évacuant un échafaudage savant et un agencement calculé en vue de la translatio spirituelle du lecteur. Les deux modes de lecture ne sont peut-être pas exclusifs, mais la lecture basée sur la seule hypothèse du livre de sermons est réductrice. Pour perfectionner notre compréhension de l'Ovide moralisé, il faudrait se pencher non seulement sur le discours de doctrine et d'actualité politique qu'il véhicule, mais aussi sur les modes de structuration du texte dans les manuscrits, sur l'évolution des gloses et sur l'iconographie. Il convient ainsi d'évaluer en parallèle, ou en complément de l'hypothèse des sermons, une réception plus courtoise et curiale de l'Ovide moralisé. Cette lecture permettrait aussi de mesurer l'évolution et la montée en puissance de l'orateur sur le champ de l'écriture engagée à la fin du Moyen Âge.

Virginie Minet-Mahy Université catholique de Louvain et Université d'Anvers

essoufflement de l'auteur, mais le passage de plus en plus rapide vers le sens spirituel que l'on attend d'un lecteur désormais rompu à ce type de glose. 


\begin{tabular}{|c|c|c|c|}
\hline \multicolumn{4}{|l|}{ Livre 12} \\
\hline \multicolumn{2}{|c|}{ Sujets antiques } & \multicolumn{2}{|c|}{ Sujets religieux } \\
\hline $\begin{array}{l}\text { f. } 296 / \mathrm{r} . \\
365\end{array}$ & Paris arrive en Grèce & & \\
\hline $\begin{array}{l}\text { f. } 296 \mathrm{v} / \\
366\end{array}$ & Ménélas part en Crète & & \\
\hline $\begin{array}{l}\text { f. } 296 \mathrm{v} \mathrm{/} \\
367\end{array}$ & Paris et Hélène & & \\
\hline $\begin{array}{l}\text { f. } 300 / \\
368\end{array}$ & Rapt d'Hélène & & \\
\hline $\begin{array}{l}\text { f. } 300 \mathrm{v} / \\
369\end{array}$ & Paris et Hélène & & \\
\hline \multirow[t]{2}{*}{$\begin{array}{l}\text { f. } 301 \quad / \\
370\end{array}$} & Ménélas rentre en Grèce & & \\
\hline & & f. $303 / 371$ & $\begin{array}{ll}\text { Prophètes } & \text { et } \\
\text { prédicateurs } & \end{array}$ \\
\hline \multirow[t]{2}{*}{$\begin{array}{ll}303 v \quad / \\
372\end{array}$} & $\begin{array}{l}\text { Arrivée de la flotte grecque à } \\
\text { Troie }\end{array}$ & & \\
\hline & & $304 v / 373$ & $\begin{array}{l}\text { Saint Paul avec le } \\
\text { glaive (parole divine) } \\
\text { et un pénitent (croix) }\end{array}$ \\
\hline \multirow[t]{2}{*}{$305 / 374$} & $\begin{array}{l}\text { Attaque des Troyens contre la } \\
\text { flotte grecque }\end{array}$ & & \\
\hline & & $305 \mathrm{v} / 375$ & Christ en Majesté \\
\hline $306 / 376$ & Bataille & & \\
\hline \multirow[t]{2}{*}{$306 / 377$} & Cygnus contre Achille & & \\
\hline & & $307 / 378$ & Christ en croix \\
\hline \multirow[t]{2}{*}{$308 / 379$} & $\begin{array}{l}\text { Repas avec les restes de la } \\
\text { génisse du sacrifice en } \\
\text { remerciement pour la victoire } \\
\text { contre Cygnus }\end{array}$ & & Proche de la cène \\
\hline & & $308 / 380$ & Descente de la croix \\
\hline $\begin{array}{ll}308 \mathrm{v} \quad / \\
381\end{array}$ & Nestor fait le récit & & \\
\hline \multirow[t]{2}{*}{$309 / 382$} & $\begin{array}{l}\text { Enlèvement des femmes par } \\
\text { les centaures }\end{array}$ & & \\
\hline & & $312 v / 383$ & Adam et Eve \\
\hline \multirow[t]{2}{*}{$313 \mathrm{v} / 384$} & Nestor raconte & & \\
\hline & & $314 / 385$ & Moïse cornu \\
\hline \multirow[t]{2}{*}{$\begin{array}{ll}314 \mathrm{v} & / \\
386\end{array}$} & Prophétie de Calcas & & \\
\hline & & $315 \mathrm{v} / 387$ & Dieu en Majesté \\
\hline $316 / 388$ & Patrocle contre Hector & & \\
\hline
\end{tabular}




\begin{tabular}{|c|c|c|c|}
\hline & & $316 v / 389$ & Les prophètes \\
\hline $317 / 390$ & Mort de Patrocle & & \\
\hline $319 / 391$ & Mort d'Hector & & \\
\hline $\begin{array}{ll}320 \mathrm{v} & 1 \\
392 & \end{array}$ & Sépulture d'Hector & & \\
\hline $321 / 393$ & Hécube sur la tombe d'Hector & & \\
\hline $322 / 394$ & Achile et Troïlus & & \\
\hline \multirow[t]{2}{*}{$\begin{array}{ll}322 \mathrm{v} \quad / \\
395\end{array}$} & Mort d'Achille & & \\
\hline & & $\begin{array}{l}\text { 323v / } 396 \\
\text { Eglise } \\
\text { (Polyxène) }\end{array}$ & \\
\hline $324 / 397$ & $\begin{array}{l}\text { Ulysse et Ajax disputent les } \\
\text { armes d'Achille }\end{array}$ & & \\
\hline \multicolumn{4}{|l|}{ Livre 13} \\
\hline \multicolumn{2}{|c|}{12 sujets antiques } & \multicolumn{2}{|c|}{5 sujets religieux } \\
\hline $324 / 398$ & Dispute d'Ajax et Ulysse & & \\
\hline & & $329 v / 399$ & $\begin{array}{l}\text { Saint Jean-Baptiste } \\
\text { (agneau) }\end{array}$ \\
\hline \multirow[t]{2}{*}{$\begin{array}{ll}331 & \mathrm{v} / \\
400 & \\
\end{array}$} & Suicide d'Ajax & & \\
\hline & & $331 v / 401$ & $\begin{array}{l}\text { Décollement de Jean- } \\
\text { Baptiste }\end{array}$ \\
\hline \multirow[t]{2}{*}{$332 / 402$} & Incendie de Troie & & \\
\hline & & $333 / 403$ & Jugement dernier \\
\hline $334 / 404$ & $\begin{array}{l}\text { Agamemnon et son armée sur } \\
\text { un navire }\end{array}$ & & \\
\hline $334 v / 405$ & Lamentation d'Hécube & & \\
\hline $335 \mathrm{v} / 406$ & $\begin{array}{lll}\text { Hécube trouve } & \text { Polydoros } \\
\text { décapité } & & \\
\end{array}$ & & \\
\hline \multirow[t]{2}{*}{$336 / 407$} & Hécube aveugle Polymestor & & \\
\hline & & $336 \mathrm{v} / 408$ & Église et Synagogue \\
\hline $337 v / 409$ & Hécube prie Jovis & & \\
\hline $339 v / 410$ & Incendie de Troie & & \\
\hline \multirow[t]{2}{*}{$339 v / 411$} & Fuite d'Enée & & \\
\hline & & $340 \mathrm{v} / 412$ & Adam et Eve \\
\hline $341 v / 413$ & $\begin{array}{l}\text { Phébus donne à Anchise le } \\
\text { manteau et le sceptre et à } \\
\text { Enée la coupe d'or }\end{array}$ & & \\
\hline $345 / 414$ & Galathée et Scilla & & \\
\hline $349 / 415$ & Glaucus et Scilla & & \\
\hline \multicolumn{4}{|c|}{ Livre $14: 31$ images } \\
\hline \multicolumn{2}{|c|}{23 sujets antiques } & \multicolumn{2}{|c|}{8 sujets religieux } \\
\hline $351 / 416$ & Glaucus et Scilla & & \\
\hline $352 \mathrm{v} / 417$ & Enée et Didon & & \\
\hline & & $354 / 418$ & Martyre de l'Eglise \\
\hline
\end{tabular}




\begin{tabular}{|c|c|c|c|}
\hline $354 \mathrm{v} / 419$ & Départ d’Enée & & \\
\hline $355 / 420$ & Sibylle guide Énée aux enfers & & \\
\hline $358 / 421$ & Sibylle prophétise & & \\
\hline $360 \mathrm{v} / 422$ & Enée et Sibylle & & \\
\hline $361 / 423$ & Enée enterre Taijgeta & & \\
\hline $363 / 424$ & Récit d'Achéménide & & \\
\hline $364 \mathrm{v} / 425$ & $\begin{array}{l}\text { Arrivée des compagnons } \\
\text { d'Ulysse chez Circé }\end{array}$ & & \\
\hline $366 / 426$ & $\begin{array}{l}\text { Ulysse devant l'image de } \\
\text { Picus }\end{array}$ & & \\
\hline \multirow[t]{2}{*}{$366 v / 427$} & $\begin{array}{l}\text { Canens charme les oiseux par } \\
\text { son chant }\end{array}$ & & \\
\hline & & $368 / 428$ & Les prophètes \\
\hline \multirow[t]{2}{*}{$369 \mathrm{v} / 429$} & $\begin{array}{l}\text { Métamorphose de Canens en } \\
\text { vent }\end{array}$ & & \\
\hline & & $370 / 430$ & Prédicateur \\
\hline $370 v / 431$ & Circé et Ulysse & & \\
\hline $371 v / 432$ & $\begin{array}{l}\text { Énée et Lavinie et Latinus } \\
\text { (mariage ?) }\end{array}$ & & \\
\hline \multirow[t]{2}{*}{$372 / 433$} & Turnus envie un messager & & \\
\hline & & $373 / 434$ & $\begin{array}{l}\text { Persécutions (Église/ } \\
\text { Judée?) }\end{array}$ \\
\hline $374 / 435$ & $\begin{array}{l}4 \text { nymphes et l'olivier } \\
\text { sauvage }\end{array}$ & & \\
\hline $375 / 436$ & $\begin{array}{l}\text { Cybèle sauve le navire de } \\
\text { l'incendie }\end{array}$ & & \\
\hline \multirow[t]{2}{*}{$375 v / 437$} & Mort de Turnus & & \\
\hline & & $376 / 438$ & $\begin{array}{l}\text { Persécutions de } \\
\text { l'Eglise }\end{array}$ \\
\hline $377 \mathrm{v} / 439$ & Mariage de Lavinie & & \\
\hline $378 v / 440$ & Déification d'Enée & & //Trinité \\
\hline $379 / 441$ & Pomone et Vertumne & & \\
\hline $383 / 442$ & $\begin{array}{lll}\text { Naissance des } & \text { jumeaux } \\
\text { Romulus et Rémus } & \end{array}$ & & \\
\hline \multirow[t]{2}{*}{$383 v / 443$} & Romulus Trônant & & \\
\hline & & $385 v / 444$ & $\begin{array}{l}\text { Massacre } \\
\text { Innocents }\end{array}$ \\
\hline $388 / 445$ & $\begin{array}{l}\text { Romulus roi de Sabine et de } \\
\text { Rome }\end{array}$ & & \\
\hline \multirow[t]{2}{*}{$388 v / 446$} & Tristesse d'Hersilie & & \\
\hline & & $389 / 447$ & $\begin{array}{l}\text { Résurrection (Christ } \\
\text { et les trois Marie) }\end{array}$ \\
\hline
\end{tabular}


Illustrations : ms. Rouen, BM 0.4

(autorisation de reproduction BM Rouen, Conseil municipal 21/22 janvier 2002)

Figure 1: Jean-Baptiste, f. 329v

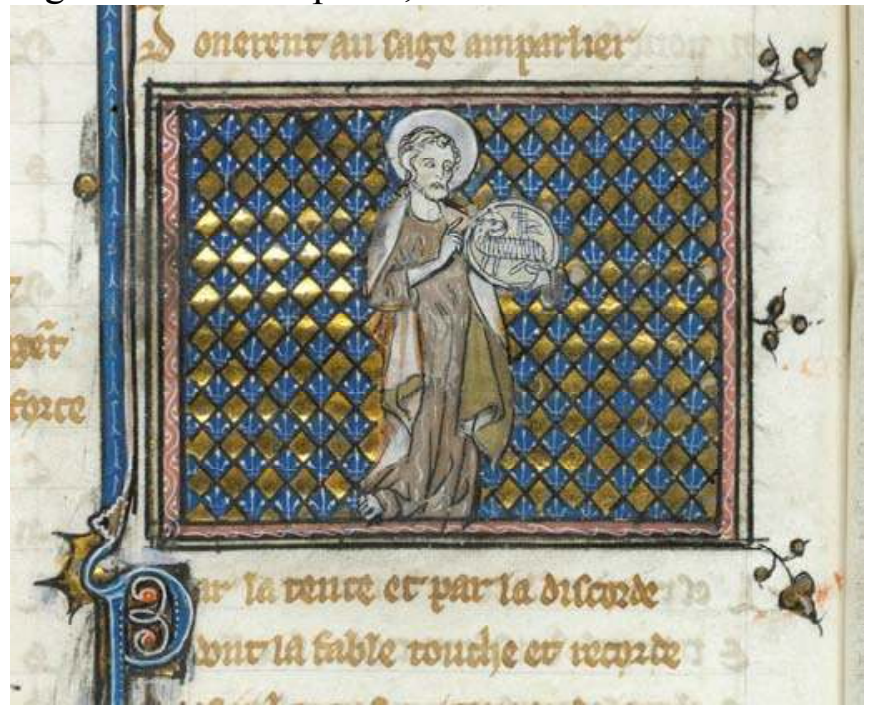

Figure 2 : Moïse Cornu, f. 314

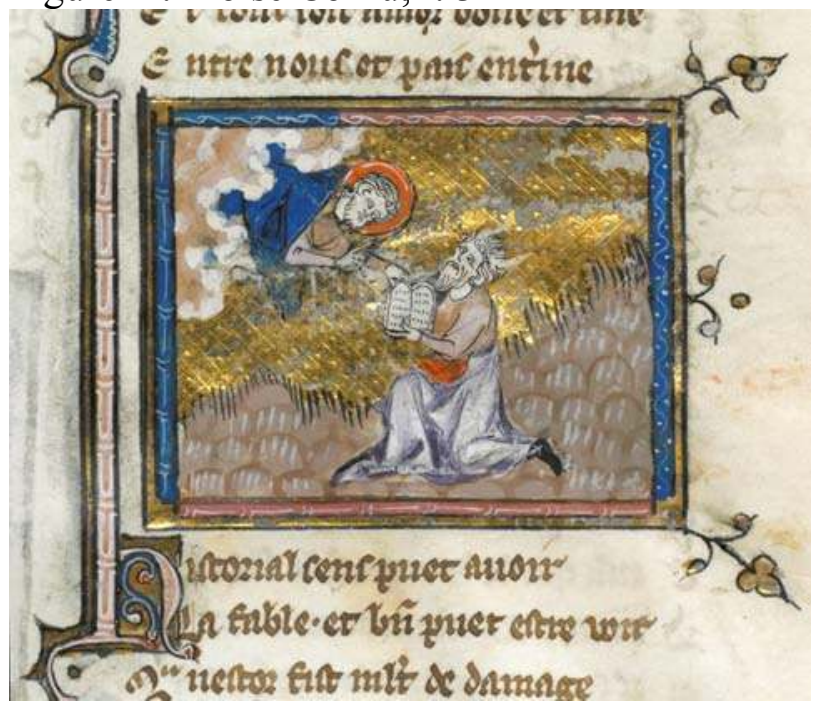


Figure 3 : f. $360 \mathrm{v}$

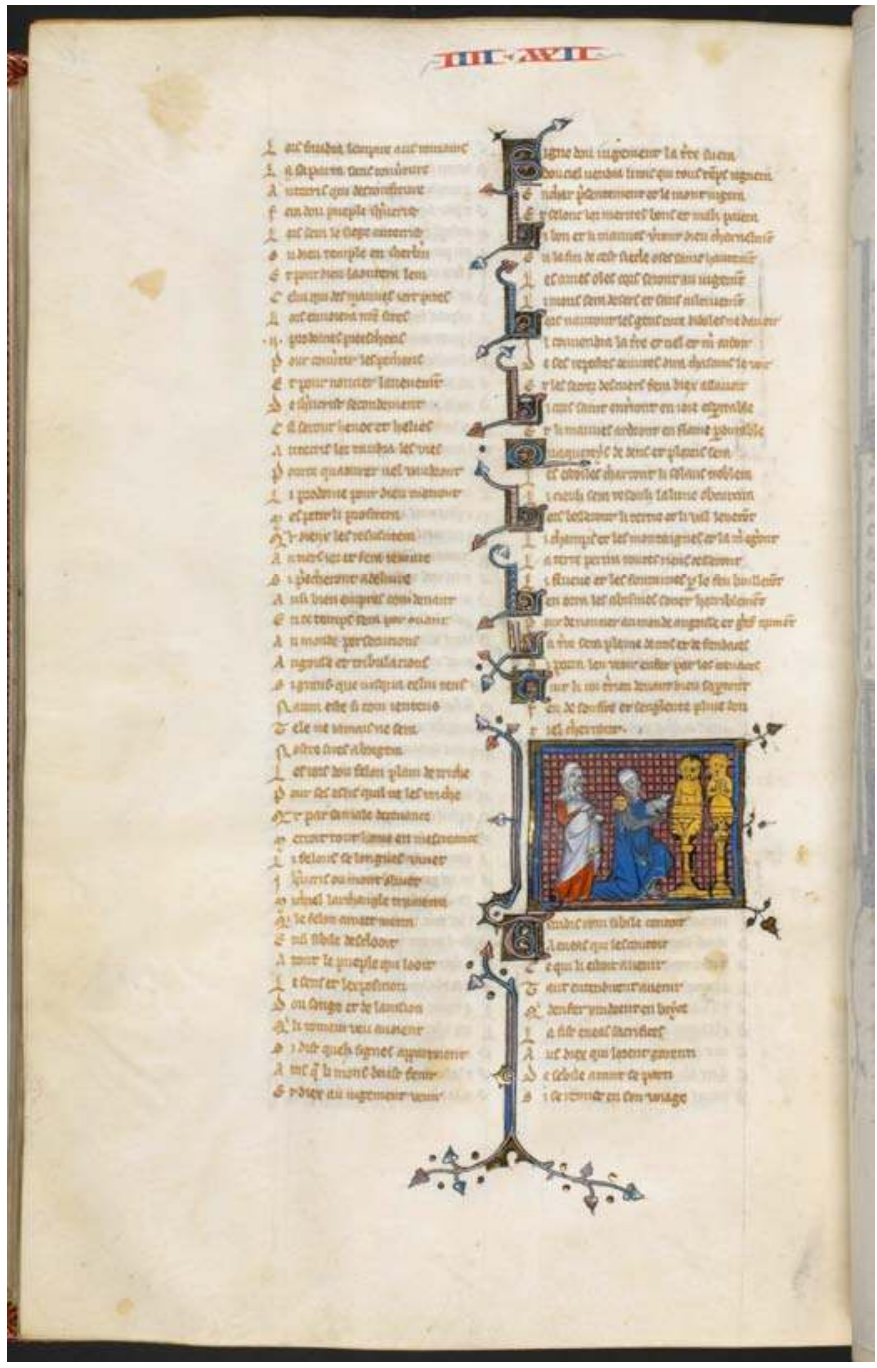


Figure 4 : Cybèle, f. 375

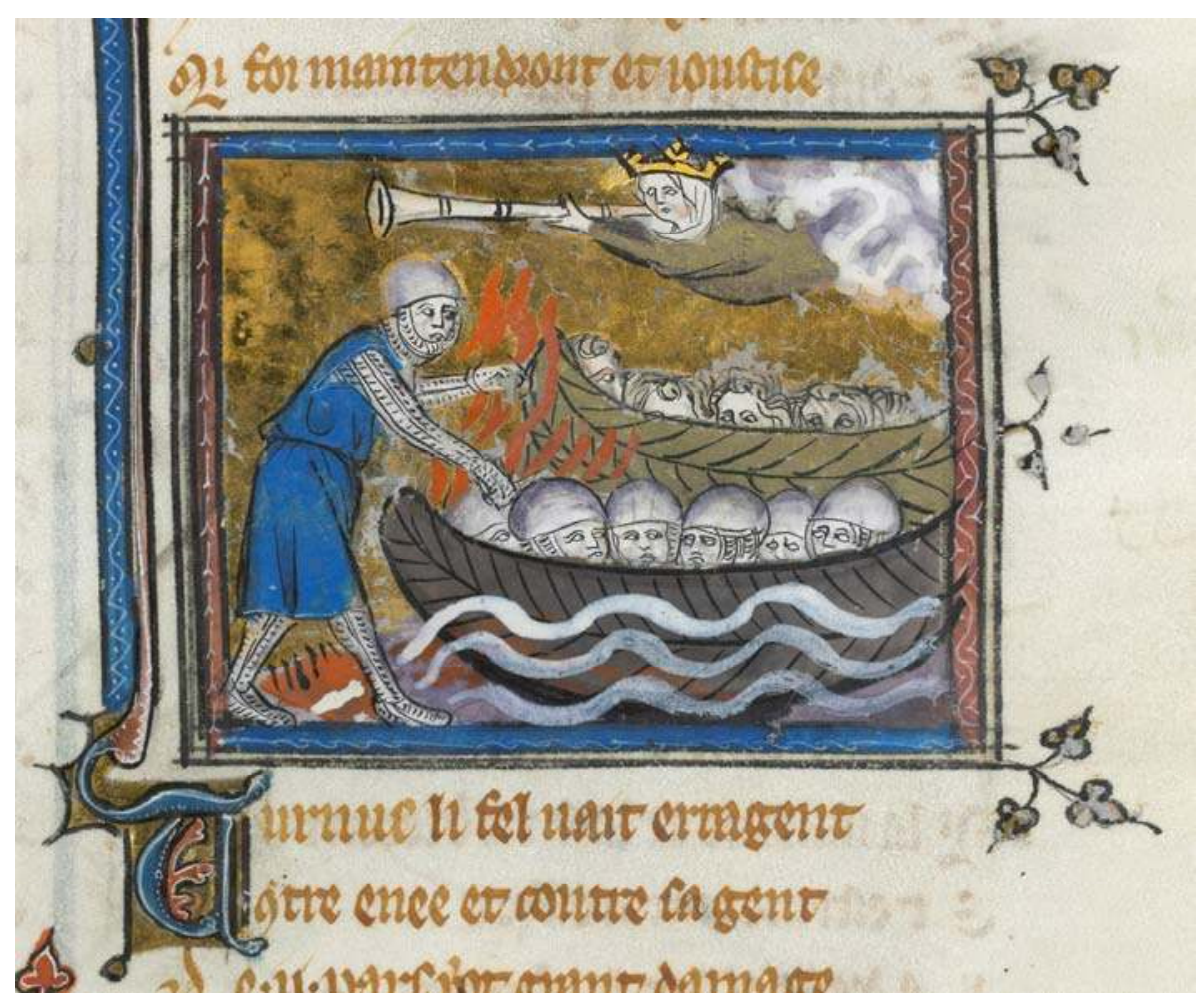

